\title{
Irregularidades na execução dos recursos públicos destinados ao combate do Aedes aegypti nos estados brasileiros: análise do perfil das justificativas apresentadas pelos gestores à luz da Teoria da Atribuição
}

\author{
DANIELE SILVA RODRIGUES ${ }^{1}$ \\ FeLIPE ROdRIGUES CRUZ ${ }^{1}$ \\ Jacqueline Veneroso Alves da CUNHA ${ }^{1}$ \\ JoÃo ESTEVÃo BARBosa NETO ${ }^{1}$
}

${ }^{1}$ Universidade Federal de Minas Gerais (UFMG) / Departamento de CiênCias Contábeis, Belo Horizonte - MG, Brasil

\begin{abstract}
Resumo
Identificar as justificativas apresentadas pelos gestores estaduais e do Distrito Federal para as irregularidades observadas na utilização dos recursos federais destinados ao combate do Aedes aegypti. Tendo por base a Teoria da Atribuição, que postula que os indivíduos indicam causas percebidas para os eventos com base em suas informações, suas crenças e suas motivações pessoais, foram analisados 27 relatórios referentes às fiscalizações realizadas durante 2016 nos 26 estados e no Distrito Federal no âmbito do Programa de Fiscalização em Entes Federativos (PFEF). A interpretação dos relatórios foi realizada por meio da análise de conteúdo, de estatísticas descritivas e do teste de Mann-Whitney. De modo geral, os resultados indicaram que a ocorrência de irregularidades classificadas nas categorias "Desempenho", "Infraestrutura" e "Licitações e Contratos" foram frequentes. Ademais, observou-se que, independentemente do tipo de irregularidade observado, a justificativa dos gestores estaduais para eventos negativos tende a ser pautada em causas externas, principalmente se o ato irregular for associado a uma possibilidade de corrupção. Essa tendência de comportamento ocorre independentemente do nível de desempenho dos gestores estaduais. Os resultados indicam que o viés autosservidor dos gestores em relação às suas irregularidades pode constituir um desafio à consecução dos objetivos do programa de combate ao mosquito Aedes aegypti, pois estes tendem a não destacar os fatores internos que afetam seus resultados.
\end{abstract}

Palavras-chave: Teoria da Atribuição. Gerenciamento de impressão. Aedes aegypti. Irregularidades. Recursos públicos.

Irregularities in the execution of public resources to combat Aedes aegypti in Brazilian states: analysis of managers' justifications based on the attribution theory

\section{Abstract}

This study aimed to identify the justifications presented by managers operating at the state level in Brazil for irregularities observed in the execution of federal resources destined to combat Aedes aegypti. According to the attribution theory, individuals allocate causes perceived for events based on their knowledge, beliefs, and personal motivations. The theory was used to analyze 27 reports on the inspections carried out within the scope of the Inspection Program in Federative Entities (IPFE) during 2016 in the 26 Brazilian states and the federal district. The attribution theory was adopted to analyze 27 reports on the inspections carried out within the scope of the Inspection Program in Federative Entities (IPFE) during 2016 in the 26 Brazilian states and the federal district. The reports were examined through content analysis, descriptive statistics, and the Mann-Whitney test. The results showed the frequent occurrence of irregularities classified in the categories performance, infrastructure, and public procurement and contracts. Furthermore, regardless of the type of irregularity observed, the state managers' justification tends to point to external causes, especially if the irregularity is associated with corruption. This behavior occurs regardless of the state managers' performance. These results indicate that managers' self-serving bias concerning irregularities can be a challenge to achieve the objectives of the Aedes aegypti mosquito control program since internal factors affecting the program's outcomes are not highlighted.

Keywords: Attribution Theory. Impression Management. Aedes aegypti. Irregularities. Public Resources.

Irregularidades en la ejecución de los recursos públicos destinados a combatir el Aedes aegypti en los estados brasileños:análisis del perfil de lasjustificaciones presentadas por los gestores a la luzdela teoría de la atribución

Resumen

Este estudio tuvo como objetivo identificar las justificaciones presentadas por los administradores de los estados y del Distrito Federal ante las irregularidades observadas en la implementación de los recursos federales destinados a combatir el Aedes aegypti. Con base en la teoría de la atribución, que postula que los individuos indican las causas percibidas de los eventos en función de su información, sus creencias y sus motivaciones personales, se analizaron 27 informes sobre las inspecciones realizadas durante 2016 en los 26 estados y el Distrito Federal dentro del alcance del Programa de Inspección de Entidades Federales (PFEF). Los informes fueron interpretados mediante análisis de contenido, estadísticas descriptivas y el test de Mann-Whitney. En general, los resultados indicaron que la ocurrencia de irregularidades clasificadas en las categorías "Rendimiento", "Infraestructura" y "Licitaciones y contratos" era frecuente. Además, se observó que, independientemente del tipo de irregularidad observada, la justificación de los gestores estatales para eventos negativos tiende a basarse en causas externas, especialmente si el acto irregular está asociado a una posibilidad de corrupción. Esta tendencia de comportamiento se da independientemente del nivel de desempeño de los administradores estatales. Estos resultados indican que el sesgo egoísta de los gestores en relación a sus irregularidades puede ser un desafío para lograr los objetivos del programa de control del mosquito Aedes aegypti, ya que tienden a no resaltar los factores internos que afectan sus resultados.

Palabras clave: Teoría de la atribución. Gestión de impresión. Aedes aegypti. Irregularidades. Recursos públicos. 
Irregularidades na execução dos recursos públicos destinados ao combate do Aedes aegypti nos estados brasileiros: análise do perfil das justificativas apresentadas pelos gestores à luz da Teoria da Atribuição
Daniele Silva Rodrigues | Felipe Rodrigues Cruz Jacqueline Veneroso Alves da Cunha João Estevão Barbosa Neto

\section{INTRODUÇÃO}

Emergências em saúde pública trazem consigo não só novas perspectivas para esta área, mas também novos desafios nas dimensões sociais, políticas, econômicas, ambientais e culturais das sociedades (Fundação Oswaldo Cruz [Fiocruz], 2020). Diante dessa adversidade, a gestão pública precisa entender quais as dificuldades e problemas a serem enfrentados, procurando combatê-los da melhor forma possível.

Barata (2000) destaca que a colonização brasileira, realizada pelos portugueses em meados do século XIX, acarretou a disseminação de muitas enfermidades trazidas pelos colonos, a exemplo da varíola e da febre amarela, que, efetivamente, provocaram epidemias no País. Mesmo que por outros fatores, esse cenário epidêmico ainda pode ser constatado no Brasil.

Um exemplo mais recente de emergência em saúde pública foi observado no ano de 2015, quando o País foi acometido por uma tríplice epidemia de zika, dengue, chikungunya, patologias transmitidas pelo mosquito Aedes aegypti. Segundo o Boletim Epidemiológico no 03/2016 divulgado pelo Ministério da Saúde (2016a), nesse ano foram notificados 1.649.008 casos prováveis de dengue (maior valor registrado desde 1990, quando o Ministério da Saúde tornou obrigatória a notificação), e 20.661 casos prováveis de febre chikungunya no País. Dentre esses casos, foram confirmados 864 óbitos. Constatou-se, ainda, a incidência do vírus zika em 19 estados brasileiros.

Outra consequência causada pelo mosquito Aedes aegypti foi o aumento no número de nascimento de crianças com microcefalia. A Secretaria de Vigilância em Saúde do Ministério da Saúde recebeu a notificação de 2.975 casos de microcefalia relacionada à infecção pelo vírus zika em 2015, dentre os quais, 37 vieram a óbito (Ministério da Saúde, 2016b). Percebe-se, portanto, que o País vivenciou uma situação de calamidade pública.

Esse contexto adverso levou o Governo Federal a declarar, em novembro de 2015, estado de Emergência em Saúde Pública de Importância Nacional (ESPIN) (Portaria n. 1.813, 2015) e convocar o Grupo Estratégico Interministerial de Emergência em Saúde Pública de Importância Nacional e Internacional (GEI-ESPII). Em dezembro do mesmo ano, por meio do GEI-ESPII, foi criado e implementado, em parceria com os estados e municípios brasileiros, o Plano Nacional de Enfrentamento ao Aedes e à microcefalia, com atuação em três eixos: i) mobilização e combate ao mosquito, ii) atendimento às pessoas; e iii) desenvolvimento tecnológico, educação e pesquisa (Ministério da Saúde, 2017a).

No eixo de mobilização e combate ao mosquito, as principais medidas foram a mobilização e capacitação de agentes comunitários de saúde, agentes de combate a endemias, profissionais da área da saúde e da área da educação para prestar orientação à população. Além disso, o Governo Federal adquiriu e disponibilizou aos estados e municípios os equipamentos e insumos necessários para aplicação de inseticidas e larvicidas (Ministério da Saúde, 2016c).

No eixo de atendimento às pessoas, o Ministério da Saúde desenvolveu e disponibilizou aos profissionais de atenção à saúde dos estados e municípios brasileiros orientações e diretrizes sobre o cuidado adequado às gestantes e aos bebês. Essas diretrizes e orientações eram focadas na prevenção da infeç̧ão pelo vírus zika e na prestação de assistência aos nascidos com microcefalia (Ministério da Saúde, 2016c). O Governo Federal incentivou, também, a realização de pesquisas que objetivassem desenvolver tecnologias capazes de diagnosticar o vírus zika, bem como a criação de ferramentas destinadas ao controle do Aedes aegypti e das patologias causadas por ele (Ministério da Saúde, 2016c).

Para implementar tais medidas, em 2016, o Governo Federal transferiu aos estados e municípios $\mathrm{R} \$ 2.493 .521 .092,92$ para serem aplicados em ações de vigilância em saúde. Em comparação a 2015, o governo aumentou em quase $47 \%$ o valor do repasse direcionado a tais ações (Tribunal de Contas da União [TCU], 2017). No entanto, apesar dos dispêndios destinados à realização dessas medidas, observa-se que não houve uma diminuição significativa na notificação das patologias originadas pelo Aedes aegypti. De acordo com o Boletim Epidemiológico no 03/2017 divulgado pelo Ministério da Saúde (2017b), em 2016 foram constatados 1.500 .535 casos prováveis de dengue, 271.824 casos prováveis de febre chikungunya e 215.319 casos prováveis de febre pelo vírus zika no País.

Um fator que pode ter contribuído para a baixa efetividade do programa é a presença de irregularidades na aplicação dos recursos destinados ao combate do mosquito Aedes aegypti. Em 2016, por meio do Programa de Fiscalização em Entes Federativos (PFEF), a Controladoria Geral da União (CGU) constatou que, em 13 dos 27 estados fiscalizados, os recursos federais destinados ao combate ao Aedes aegypti não foram aplicados de forma adequada (TCU, 2017). Foram constatadas, 
Irregularidades na execução dos recursos públicos destinados ao combate do Aedes aegypti nos estados brasileiros: análise do perfil das justificativas apresentadas pelos gestores à luz da Teoria da Atribuição
Daniele Silva Rodrigues | Felipe Rodrigues Cruz Jacqueline Veneroso Alves da Cunha João Estevão Barbosa Neto

pelos auditores da CGU, irregularidades no controle de estoques e na armazenagem de inseticidas e pesticidas, bem como falha nos processos de compras e pagamentos (CGU, 2016).

Tal constatação reforça que não basta apenas ter recursos disponíveis, é preciso que a administração pública operacionalize-os de forma eficiente e eficaz. Ou seja, torna-se necessária uma gestão que contribua para a boa aplicação dos recursos, contribuindo para uma efetiva realização dos programas e dos serviços. E, mais do que isso, caso determinada ação ou serviço público não atinja os objetivos previstos, faz-se necessário que os gestores responsáveis demonstrem e expliquem as causas da não efetividade dessa gestão ou de irregularidades detectadas. Essa explicação deve ser de iniciativa dos gestores, para que, levando-se em conta seu comportamento bem como de outras pessoas, as causas e efeitos de sua administração sejam analisados, evitando-se, com isso, o erro ou injustiça no julgamento sobre o outro (Gouveia, Clemente, Angel \& Martinez, 2000).

Esse comportamento pode ser explicado com base no arcabouço da Teoria da Atribuição, elaborada por Heider (1958). De acordo com essa teoria, as pessoas procuram conhecer as razões das ações realizadas por elas e outros, atribuindo causas a comportamentos que elas veem, em vez de assumir que esses comportamentos são aleatórios. Isso permite que as pessoas assumam algum sentimento de controle sobre seus próprios comportamentos e situações. Assim, as atribuições são críticas para o gerenciamento porque as causas percebidas do comportamento podem influenciar os julgamentos e ações dos gerentes e funcionários.

No caso do PFEF, em 2016, ao tomar ciência sobre as irregularidades observadas, os gestores puderam apresentar justificativas para a CGU em relação a essas. Dentre as justificativas observadas nos relatórios, citam-se a falta de treinamento, a insuficiência de recursos etc. (CGU, 2016). Nesse contexto, há margem para a prática de gerenciamento de impressão, pois os gestores podem atribuir causas que não são de seu controle às irregularidades observadas, mesmo que tenham alguma influência sobre tais causas.

Diante do exposto e com base na Teoria da Atribuição, é possível avaliar o perfil das justificativas apresentadas pelos gestores, uma vez que, de acordo com a teoria, os indivíduos indicam causas percebidas para os eventos com base em suas informações, suas crenças e suas motivações pessoais (Kelley \& Michela, 1980). Sob esse escopo teórico, o gerenciamento de impressão é marcado pela manifestação do viés autosservidor (serf-serving bias), que normalmente se manifesta como uma tendência de atribuir eventos positivos (ex.: bom desempenho organizacional) a causas internas (ex: capacidade do gestor) e eventos negativos (ex.: desempenho organizacional ruim) a causas externas (ex: economia desfavorável) (Tessarolo, Pagliarussi \& Luz, 2010).

Conforme indicam Kelley e Michela (1980), a reputação ou o status social podem afetar as atribuições causais feitas pelo indivíduo e, consequentemente, a objetividade de suas deduções. Logo, o gestor pode desconsiderar a qualidade do conteúdo informacional dos relatórios em prol de seus interesses particulares, apresentando justificativas (causas) para as irregularidades que não prejudicam sua imagem (ou evitam depreciações dela).

Desse modo, assume-se que a forma como os gestores justificam as irregularidades observadas pela CGU, considerando suas motivações pessoais e suas informações, pode acentuar a assimetria informacional entre a sociedade e a administração pública. Isso poderia eventualmente prejudicar os processos de tomada de decisão por parte dos membros da sociedade, tornando a temática de interesse público.

A literatura tem se preocupado em descrever essas irregularidades e analisar as suas causas ou consequências (Araújo \& Santos, 2018; Batista 2013; Laurinho Dias \& Mattos, 2017; Olivieri, Martinelli, Massucato \& Silva, 2018; Rodrigues, Santos \& Faroni, 2018). Porém a o conteúdo das justificativas ainda não foi objeto de análise suficientemente atenta por parte da academia.

Diante desse contexto, além de entender os tipos de irregularidade que podem ter ocorrido na gestão dos recursos federais destinados aos estados brasileiros para o combate do mosquito, é importante analisar o perfil das justificativas apresentadas pelos gestores estaduais, considerando suas intenções subjacentes. Logo, este estudo busca responder à seguinte questão de pesquisa, que é também o objetivo geral do trabalho: Qual é o perfil das justificativas apresentadas pelos gestores estaduais em relação às irregularidades observadas na execução dos recursos federais direcionados ao combate do Aedes aegypti?

Em uma perspectiva motivacional, torna-se relevante evidenciar possíveis problemas na elaboração dos documentos que seriam oriundos dos interesses pessoais de gestores públicos. As atribuições causais que os gestores processam a respeito do sucesso ou do insucesso do Plano Nacional de Enfrentamento ao Aedes e à Microcefalia consistem em fatores determinantes de suas expectativas relativas às suas capacidades e ao seu desempenho. Tal atitude pode afetar a percepção pública, gerando 
Irregularidades na execução dos recursos públicos destinados ao combate do Aedes aegypti nos estados brasileiros: análise do perfil das justificativas apresentadas pelos gestores à luz da Teoria da Atribuição
Daniele Silva Rodrigues | Felipe Rodrigues Cruz Jacqueline Veneroso Alves da Cunha João Estevão Barbosa Neto

prejuízos à sociedade em termos informacionais. Assim, é possível entender os estímulos mediadores, mais salientes frente aos sujeitos, os quais se devem a processos cognitivos e respostas individuais que estes passam a produzir sobre o fenômeno vivido (Formiga, 2004).

Conhecer e compreender, também, as atribuições (justificativas) dos gestores a suas ações, no âmbito do controle social, contribui para que os cidadãos, bem como toda a sociedade organizada, possam participar da fiscalização do gasto público, avaliando as ações governamentais e reivindicando a adequada aplicação dos recursos públicos. Embora o gestor dos recursos públicos tenha a obrigação de aplicá-los de acordo com a legislação pertinente, contribuindo para o bem-estar de toda a sociedade, nem sempre isso se verifica. Por meio de pesquisas que evidenciem e tentem explicar o comportamento e as ações dos gestores, os cidadãos são capazes de incrementar o trabalho desses dirigentes, melhorando, consequentemente, seus resultados. Essa participação cidadã na gestão pública influencia na tomada da decisão administrativa, seja instruindo a Administração para que adote medidas que atendam ao interesse público, seja exercendo o controle sobre a ação do Estado.

No meio acadêmico e científico, destaca-se que, embora a Teoria da Atribuição tenha sido amplamente utilizada nos estudos organizacionais, principalmente no contexto contábil (Aerts, 2005; Merkl-Davies \& Brennan, 2017), não foi utilizada para avaliar as narrativas elaboradas por gestores do setor público. Em virtude do exposto, o presente estudo apresenta como outro aspecto relevante o fato de realizar uma adaptação da utilização da Teoria da Atribuição em estudos organizacionais para o setor público, com base em um estudo exploratório dos relatórios da CGU. Isso permite a análise de informações da administração pública sob uma ótica inovadora.

\section{REFERENCIAL TEÓRICO}

\section{Irregularidades na gestão dos recursos públicos federais}

A CGU realiza a fiscalização da gestão dos recursos públicos federais destinados aos estados e municípios brasileiros. O produto final dessas fiscalizações são um relatório por ente federado fiscalizado, que contém a descrição das irregularidades encontradas pelos auditores da CGU, e, ainda, as justificativas apresentadas pelos gestores em relação às evidências encontradas (CGU, 2018; Zamboni, 2012).

A literatura brasileira utiliza os relatórios das fiscalizações realizadas pelos auditores da CGU como base de dados para o levantamento das irregularidades que ocorreram na gestão dos recursos públicos. Esses relatórios são oriundos, principalmente, do Programa de Fiscalização por Sorteios Públicos (PFPS) criado em 2003 (atualmente intitulado Programa de Fiscalização em Entes Federativos [PFEF]). Os trabalhos de Albuquerque e Ramos (2006) e Ferraz e Finan (2008) são considerados os precursores na utilização desses relatórios. Os autores consideraram o número de irregularidades reportadas nos relatórios de fiscalizações da CGU como proxy do comportamento corrupto dos gestores públicos municipais.

Estudos recentes também empregaram as constatações presentes nos relatórios da CGU como base de dados para o levantamento das irregularidades que ocorreram na gestão dos recursos públicos federais pelos estados e municípios brasileiros. Como exemplos, podem ser citados os estudos de Araújo e Santos (2018); Batista (2013); Batista, Rocha e Santos (2020); Laurinho et al. (2017); Lopes e Doula (2019); Olivieri et al. (2018); Rodrigues et al. (2018); e Rodrigues, Faroni, Santos, Ferreira e Diniz (2020) que consideraram os relatórios oriundos do PFSP, bem como o trabalho de Paschoal, Santos e Faroni (2020), no qual foram analisados os relatórios oriundos do programa de fiscalização "Demandas Externas".

Batista (2013), por exemplo, analisou a influência da dinâmica política na incidência de corrupção e na má gestão nos municípios brasileiros durante 2003 e 2004 utilizando os relatórios da CGU. A autora classificou as irregularidades reportadas nos relatórios de fiscalização em 19 categorias. As irregularidades mais frequentes encontradas por Batista (2013) foram falhas na execução do programa ou obra (uso dos recursos públicos em ações distintas daquelas para as quais foram designados e obras inacabadas ou não iniciadas) e falhas e fraudes nos processos licitatórios (direcionamento de licitações e erros na documentação).

Por sua vez, Laurinho et al. (2017) investigaram as irregularidades que ocorreram nos processos licitatórios da área da saúde pública dos municípios. Por meio da análise de 102 relatórios provenientes do PFPS e referentes ao período de 2010 a 2012, os autores classificaram as irregularidades constatadas pelos auditores da CGU em duas categorias: corrupção e ineficiência. 
Irregularidades na execução dos recursos públicos destinados ao combate do Aedes aegypti nos estados brasileiros: análise do perfil das justificativas apresentadas pelos gestores à luz da Teoria da Atribuição
Daniele Silva Rodrigues | Felipe Rodrigues Cruz Jacqueline Veneroso Alves da Cunha João Estevão Barbosa Neto

A categoria que apresentou o maior número de constatações foi a ineficiência, e de forma recorrente foram verificadas irregularidades em documentos do processo licitatório e não realização de licitação.

Resultados similares aos de Batista (2013) e de Laurinho et al. (2017) foram encontrados por Rodrigues et al. (2018) e por Olivieri et al. (2018). Rodrigues et al. (2018), em um levantamento de irregularidades que ocorreram na gestão do Programa de Aceleração do Crescimento (PAC) durante os anos de 2008 e 2009, observaram nos municípios fiscalizados a frequência de indícios de erros e fraudes nos processos licitatórios e fragilidades na gestão dos recursos destinados ao PAC (erros na documentação dos projetos enviados ao governo federal e morosidade na solução de pendências).

Concentrando-se nos recursos públicos federais destinados à educação básica dos municípios brasileiros, Olivieri et al. (2018) analisaram 51 relatórios provenientes do PFSP no ano de 2014 e identificaram evidências de mau uso dos recursos, bem como corrupção. Os autores constataram irregularidades recorrentes na gestão de infraestrutura das escolas (armazenagem inadequada de alimentos e veículos de transporte escolar em condições precárias) e fraudes em licitações (conluio, fracionamento de despesas, uso inadequado da dispensa de licitação).

O trabalho de Araújo e Santos (2018) teve como objetivo analisar as irregularidades que ocorreram na gestão dos recursos públicos federais destinados aos estados brasileiros, recorrendo a 106 relatórios referentes ao período de 2004 a 2009 e de 2016. Os principais achados da pesquisa indicaram que existe similaridade nos tipos de irregularidades encontradas pela literatura que considerou os municípios brasileiros. De acordo com Araújo e Santos (2018), foram recorrentes o superfaturamento nas compras realizadas pelos estados e, também, a incidência de fragilidades na aplicação e controle dos recursos públicos federais (controle de estoque inadequado e instalações precárias).

Lopes e Doula (2019) investigaram as irregularidades que ocorreram no processo de compras de gêneros alimentícios realizadas pelos municípios brasileiros com recursos oriundos do Programa Nacional de Alimentação Escolar (PNAE). Foram analisados os relatórios de fiscalizações de 108 municípios das regiões Norte e Nordeste referentes ao período de 2009 a 2016. Corroborando os achados dos estudos citados anteriormente, Lopes e Doulas (2019) verificaram que as irregularidades no processo de compras públicas mais recorrentes foram: dispensa indevida de licitação, irregularidades na montagem de processos licitatórios e sobrepreço e superfaturamento.

Assim como o estudo de Olivieri et al. (2018) e de Lopes e Doula (2019), o trabalho de Rodrigues et al. (2020) centrou-se na análise das irregularidades que ocorreram na execução dos recursos púbicos federais destinados à educação básica dos municípios brasileiros. Rodrigues et al. (2020) analisaram 323 relatórios oriundos das fiscalizações realizadas pela CGU entre 2011 e 2015, bem como classificaram as irregularidades apontadas em duas categorias: corrupção e má gestão. Na categoria de corrupção, os referidos autores observaram que foram frequentes os indícios de i) fraude na elaboração do edital dos processos licitatórios e no curso da realização do certame e ii) realização de pagamentos sem comprovação da realização da compra ou do fornecimento do produto ou serviço. No que diz respeito às irregularidades pertencentes ao constructo "má gestão", foram recorrentes as falhas no controle dos estoques de insumos e afins.

Batista et al. (2020) utilizaram as indicações de incongruências presentes nos relatórios de fiscalização da CGU como indicador da performance governamental. Essas indicações foram classificadas como corrupção ou má gestão. Assim como nos estudos citados anteriormente, a categoria corrupção abrangeu as incongruências relacionadas às licitações (ex.: montagem de processo licitatório, direcionamento de licitação e sobrepreço). As demais foram classificadas na categoria de má gestão (inoperância dos conselhos municipais e utilização de veículos inadequados para o transporte de alunos). Batista et al. (2020) destacam que os números expressivos de irregularidade indicam a necessidade de adoção de medidas que visem reduzir esses problemas na implementação de políticas públicas.

Por sua vez, para o desenvolvimento da sua pesquisa, Paschoal et al. (2020) consideraram outro programa de fiscalização da CGU, o "Demandas Externas". Além das irregularidades observadas nos relatórios gerados neste programa, os autores também analisaram as justificativas que os gestores municipais apresentaram para a sua ocorrência. Essas informações presentes nos relatórios da CGU foram analisadas à luz das teorias Triângulo e Diamante da Fraude. A amostra contemplada pela pesquisa abrangeu 259 relatórios relativos ao interstício temporal de janeiro de 2015 a maio de 2018.

Os achados da pesquisa de Paschoal et al. (2020) indicaram que os quatro fatores do arcabouço conceitual das teorias Triângulo e Diamante da Fraude estavam presentes nas observações e justificativas contidas nos relatórios, quais sejam: oportunidade, incentivo, racionalização e capacidade. As justificativas apresentadas pelos gestores foram classificadas no 
Irregularidades na execução dos recursos públicos destinados ao combate do Aedes aegypti nos estados brasileiros: análise do perfil das justificativas apresentadas pelos gestores à luz da Teoria da Atribuição
Daniele Silva Rodrigues | Felipe Rodrigues Cruz Jacqueline Veneroso Alves da Cunha João Estevão Barbosa Neto

fator racionalização. Em relação ao conteúdo, os autores observaram que os gestores utilizaram justificativas relativas: a problemas pessoais enfrentados pelo indivíduo; ato moral socialmente válido; comparação com o ato realizado por outros gestores para reduzir a gravidade do ato praticado; deslocamento da responsabilidade para terceiros; e vitimização (indivíduo alega que é "forçado a fazer").

Os resultados dos estudos apresentados anteriormente evidenciam similaridade nos tipos de irregularidades que ocorrem na gestão dos recursos públicos federais destinados a distintos programas das áreas de saúde, educação, saneamento básico e assistência social. Esse contexto evidencia que irregularidades similares podem ter ocorrido na aplicação dos recursos destinados a outras ações, como a ação de combate do Aedes aegypti, objeto de estudo desta pesquisa. Destaca-se que não foram encontrados estudos que abordaram especificamente a gestão destes recursos. Nota-se, ainda, que existem poucos trabalhos que analisaram os resultados das fiscalizações realizadas pela CGU nos estados brasileiros.

Percebe-se que grande parte da literatura debruçou-se sobre a classificação das irregularidades encontradas nos relatórios da CGU, agrupando-as em atos de corrupção ou má utilização de recursos públicos, bem como possíveis subclassificações. No entanto, outra informação contida nos relatórios de fiscalização da CGU são as justificativas apresentadas pelos gestores em relação às irregularidades apontadas pelos auditores da Controladoria. Esse aspecto dos relatórios tem sido negligenciado pela literatura, com poucas exceções, como o trabalho de Paschoal et al. (2020), que consideraram como arcabouço teórico as teorias Triângulo e Diamante da Fraude na análise do conteúdo dos relatórios de fiscalizações da CGU.

Assume-se que o conhecimento e a compreensão de como os gestores justificam seus atos na aplicação dos recursos da máquina pública podem contribuir para a fiscalização do gasto público por parte da sociedade. Essa análise permite identificar a capacidade dos gestores de assumir responsabilidade por seus atos, bem como propicia à sociedade um olhar crítico sobre a forma como os agentes públicos se expressam ao justificar irregularidades em sua gestão.

Desse modo, destaca-se que a Teoria da Atribuição oferece um arcabouço teórico particularmente interessante para a avaliação do perfil das justificativas apresentadas pelos gestores públicos com base em explicações motivacionais. A teoria pode auxiliar especificamente no entendimento de como os gestores atribuem causalidade às irregularidades apontadas em sua gestão dos recursos públicos, abordando fatores motivacionais e a capacidade de compreensão destes fatores por parte dos agentes analisados.

\section{Teoria da Atribuição}

A Teoria da Atribuição baseia-se na obra de Heider (1958). O autor se preocupa com "questões de superfície", que são eventos que ocorrem no cotidiano em um nível consciente, em lugar dos processos inconscientes estudados pela psicologia. Ele indica que as relações humanas tidas como "óbvias" ou "intuitivamente entendidas" podem ser tão desafiadoras e psicologicamente significativas quanto os fenômenos mais profundos e estranhos. Birnberg, Luft e Shields (2007) afirmam que Heider iniciou o estudo de como as pessoas atribuem causas aos seus comportamentos, assim como aos comportamentos de outras pessoas, para que possam explicar e prever comportamentos em seus ambientes.

Um comportamento positivo, incluindo o sucesso, tem o potencial de melhorar a autoestima do responsável causal do comportamento, segundo Kelley e Michela (1980). Os autores afirmam que a motivação para a "automelhoria" (self-enhancement) deve resultar na autoatribuição (atribuição a causa interna) de comportamentos positivos. Argumentam que, de forma semelhante, comportamentos negativos podem ter implicações negativas para a autoestima do indivíduo, a menos que a responsabilidade causal seja atribuída a um fator não controlado pelo gestor (atribuição a causa externa), o que seria uma forma de autoproteção.

Para Birnberg, Frieze e Shields (1977), as pesquisas na área da Teoria de Atribuição indicam que as atribuições do indivíduo são uma função conjunta das informações que este possui sobre a situação imediata, assim como de suas tendências estáveis de fazer atribuições particulares (de suas motivações). De forma mais específica, Kelley e Michela (1980) afirmam que a Teoria da Atribuição pressupõe que as atribuições causais dos indivíduos são afetadas por suas informações, suas crenças e suas motivações. Logo, uma atribuição causal equivocada realizada por uma pessoa pode originar tanto do viés autosservidor quanto de suas limitações cognitivas. 
Irregularidades na execução dos recursos públicos destinados ao combate do Aedes aegypti nos estados brasileiros: análise do perfil das justificativas apresentadas pelos gestores à luz da Teoria da Atribuição
Daniele Silva Rodrigues | Felipe Rodrigues Cruz Jacqueline Veneroso Alves da Cunha João Estevão Barbosa Neto

Em consonância com o exposto, Aerts (2005) afirma que o modelo informacional da assimetria atribucional enfatiza as limitadas capacidades de processamento da informação humana em alcançar uma compreensão causal dos eventos, destacando que as pessoas tendem a esperar a obtenção de resultados favoráveis. De outro modo, uma interpretação motivacional dá mais ênfase às consequências do processo de atribuição ao próprio atribuidor, que podem ocasionar uma atribuição enviesada. No entanto, o autor constata que, se os fundamentos motivacionais dos vieses atributivos autosservidores forem de fato cruciais, seja de maneira isolada ou em conjunto com influências informacionais, o efeito destes vieses deve ficar claro em contextos de incentivos fortes para o gerenciamento de impressões (Aerts, 2005).

Diante da discussão exposta, o presente estudo parte da premissa de que a interpretação motivacional é essencial para o entendimento das atribuições causais realizadas por parte dos gestores estaduais. Essa asserção justifica-se pela forte influência da vida política do gestor, a qual implica a necessidade de que este apresente uma "boa imagem" perante a sociedade. Desse modo, na próxima seção apresenta-se uma interpretação motivacional derivada da Teoria da Atribuição aplicável ao setor público.

\section{Aplicação da Teoria da Atribuição ao setor público}

Para entender a utilidade da Teoria da Atribuição no presente estudo, foi realizado um paralelo com estudos organizacionais que a utilizam. Embora a teoria tenha sido amplamente aplicada aos estudos organizacionais (Aerts, 2005; Merkl-Davies \& Brennan, 2017), ainda não há um arcabouço teórico apropriado para o setor público. O presente trabalho buscou apresentar uma adaptação dessa teoria para aplicá-la ao setor público.

Aerts (2005) indica que os estudos que avaliam a atribuição causal no contexto das organizações com base nos relatórios financeiros anuais documentaram uma tendência de atribuição dos resultados ou efeitos positivos às ações da própria companhia, enquanto os resultados negativos são associados a fatores externos à companhia ou ao acaso. $\mathrm{O}$ autor complementa que esse padrão de explicação é considerado como autosservidor justamente por definir as situações de forma vantajosa para a companhia. Tessarolo et al. (2010) constataram que as atribuições autosservidoras são uma instância de justificativa causal que permite ao gestor evitar a culpa pelas "más notícias" (ex: queda nas vendas, queda nos lucros etc.) descritas nos relatórios anuais.

Birnberg et al. (2007) afirmam que muitos estudos observaram que a pessoa focal tende a atribuir seu próprio comportamento a causas externas. Os autores indicam que, na contabilidade gerencial, esta constatação permite criar uma base para explicar e prever como indivíduos irão justificar, de forma subjetiva, os desvios observados entre o desempenho esperado com base no orçamento e o desempenho efetivamente observado na prática. Conforme exposto anteriormente, quando sua capacidade pode ser colocada em questionamento, o gestor tende a fazer atribuições causais com base em fatores externos (Kelley \& Michela, 1980).

Neste estudo, assume-se que o padrão de comportamento autosservidor é observado quando os gestores públicos necessitam justificar as irregularidades apontadas pelos auditores da CGU, uma vez que estas podem ser comparadas com as "más notícias" observadas nos contextos organizacionais ou com os desvios observados em relação aos orçamentos. Assim, parte-se da premissa de que os gestores estaduais justificarão a maioria das irregularidades levantadas pela CGU associando-as a causas externas.

Essa premissa é adequada para o contexto público por levar em consideração as diferentes metas apresentadas pelos gestores públicos em análise (gestores estaduais). Enquanto os gestores organizacionais necessitam atingir metas de lucros, evitar desvios no orçamento etc., os gestores públicos apresentam metas que podem ser bastante distintas daquelas observadas no contexto organizacional privado. Particularmente, assume-se que estes gestores irão focar na melhoria de sua imagem perante a sociedade, visto que seu foco é a manutenção do cargo público ou mesmo a busca por novas oportunidades dentro do meio político.

No presente estudo, uma vez que se analisa a aplicação de recursos para o controle do Aedes aegypti, os desvios quanto ao comportamento desejável incluem fatores como irregularidades no controle de estoques e na armazenagem de inseticidas e larvicidas, problemas em processos licitatórios e falha nos processos de pagamentos, dentre outros. $O$ viés autosservidor acarreta, por parte dos gestores estaduais, a atribuição da "culpa" por essas irregularidades a fatores externos, visando melhorar sua imagem ou evitar possíveis depreciações desta perante a população. Logo, assume-se que o viés político resulta em menor accountability (baixo nível de transparência), o que é prejudicial ao processo eleitoral e à sociedade. De acordo com o exposto, pressupõe-se esse tipo de comportamento tanto por parte de gestores de estados com melhor desempenho (com menor número de irregularidades) quanto por aqueles de estados menos eficientes. 
Irregularidades na execução dos recursos públicos destinados ao combate do Aedes aegypti nos estados brasileiros: análise do perfil das justificativas apresentadas pelos gestores à luz da Teoria da Atribuição
Daniele Silva Rodrigues | Felipe Rodrigues Cruz Jacqueline Veneroso Alves da Cunha João Estevão Barbosa Neto

\section{PROCEDIMENTOS METODOLÓGICOS}

\section{Coleta de dados}

Os relatórios do 2 Ciclo do PFEF da CGU, realizado durante 2016 nos 26 estados e no Distrito Federal, são a base de dados desta pesquisa. O PFEF surgiu em 2015, após a reformulação do antigo PFPS da CGU. A principal mudança do PFPS para o PFEF foi na metodologia de seleção dos entes federativos (estados e municípios) a serem fiscalizados. Além da metodologia de sorteios públicos aplicada no PFPS, no PFEF são utilizados mais dois critérios de seleção, quais sejam: i) censo: todos os entes federativos da amostra são fiscalizados, e ii) matriz de vulnerabilidade: são escolhidos os entes federativos mais vulneráveis à ocorrência de irregularidades (CGU, 2018).

Assim como no PFPS, no PFEF os auditores da CGU realizam uma visita in loco aos entes federativos selecionados. Essa visita tem como objetivo examinar as contas e documentos, realizar inspeção pessoal e física das obras e serviços em realização, além de coletar informações da população por meio de entrevistas e questionários. O produto final da fiscalização são os relatórios emitidos pelos auditores da CGU, que incluem: i) descrição dos programas e suas respectivas ações fiscalizadas (quantidade de ações fiscalizadas e o montante de recursos destinados a tais ações); ii) descrição dos indícios de atos irregulares encontrados pelos auditores da CGU na execução dos programas que utilizam recursos federais; e iii) as justificativas dos governadores em relação às evidências encontradas e o julgamento dessas justificativas pela CGU (CGU, 2018).

Dessa forma, com a estrutura dos relatórios do PFEF, foi possível a realização do levantamento das irregularidades na aplicação dos recursos públicos federais destinados aos 26 estados brasileiros e ao Distrito Federal para o combate do Aedes aegypti, bem como a coleta das justificativas dos gestores estaduais em relação à ocorrência dessas irregularidades. Tais irregularidades e justificativas estão descritas nos 27 relatórios de fiscalização do 20 Ciclo do PFEF, em 2016, cujo objetivo foi verificar "[...] a regularidade da aplicação dos recursos públicos federais descentralizados a todos os 26 governos estaduais e ao Distrito Federal" durante o ano de 2015 (CGU, 2016).

\section{Procedimentos de análise}

Foi adotada a técnica de Análise de Conteúdo para interpretar e classificar as indicações feitas pelos auditores e as justificativas dos gestores presentes no corpus constituído por relatórios de fiscalização da CGU. O principal método de análise utilizado foi o categorial, que consiste em um processo de classificação do conteúdo analisado conforme categorias previamente definidas (Bardin, 1977). Por fim, foram realizados procedimentos estatísticos para analisar se há associação entre o viés autosservidor por parte dos gestores e o nível de desempenho dos estados.

Em consonância com outros estudos da literatura que analisaram corpora oriundos da atividade fiscalizadora da CGU, adotou-se a Análise Estruturada de Textos [AET] (Januzzi, 2011; Olivieri et al., 2018). Pode-se descrever a AET como

[...] uma das técnicas de Análise de Conteúdo empregada em situações em que se requer uma interpretação estruturada - formal, padronizada, objetivada - de ideias, mensagens e conteúdo informacional presentes em documentos, textos, artigos ou corpus de modo geral (Januzzi, 2011).

Em conformidade com Olivieri et al. (2018), foram seguidos os seguintes passos, uma vez que se demonstraram adequados à temática e aos objetivos do presente estudo: i) identificação das irregularidades apontadas pela CGU na aplicação de recursos públicos federais destinados ao combate do Aedes aegypti; ii) elaboração de um sistema de codificação com base nos objetivos do estudo para classificar os dados obtidos por meio dos relatórios da CGU; iii) teste do sistema de classificação; iv) aplicação do sistema de classificação; v) análise da confiabilidade da codificação; e, por fim, vi) análise e interpretação dos resultados.

Para a primeira etapa, foram coletados dados sobre as irregularidades apontadas nos relatórios do PFEF, conforme exposto na seção anterior. Na segunda etapa, a descrição das categorias utilizadas na classificação para irregularidades e justificativas são apresentadas nos Quadros 1 e 2. No Quadro 1, são apresentados os critérios de classificação para as indicações de irregularidades pela CGU e para as justificativas dos gestores quanto à aplicação dos recursos públicos federais destinados aos estados brasileiros para o combate ao Aedes aegypti. 
Irregularidades na execução dos recursos públicos destinados ao combate do Aedes aegypti nos estados brasileiros: análise do perfil das justificativas apresentadas pelos gestores à luz da Teoria da Atribuição
Daniele Silva Rodrigues | Felipe Rodrigues Cruz Jacqueline Veneroso Alves da Cunha João Estevão Barbosa Neto

Sistema de codificação empregado na análise das irregularidades e das justificativas

\begin{tabular}{|c|c|c|}
\hline \multicolumn{3}{|c|}{ Sistema de codificação empregado na análise das irregularidades } \\
\hline Categoria & Código & Descrição \\
\hline Licitações e Contratos & LIC & - Irregularidades na execução dos processos licitatórios. \\
\hline Desvio de recursos & DR & $\begin{array}{l}\text { - Falta de comprovação dos custos incorridos na prestação dos serviços } \\
\text { e da regularidade dos pagamentos. } \\
\text { - Superfaturamento. } \\
\text { - Sobrepreço. }\end{array}$ \\
\hline Desempenho & DES & $\begin{array}{l}\text { - Intempestividade na aplicação dos recursos públicos federais destinados } \\
\text { ao combate do Aedes aegypti. } \\
\text { - Insuficiência de ações de combate ao mosquito Aedes aegypti. }\end{array}$ \\
\hline Infraestrutura & INFRA & $\begin{array}{l}\text { - Problemas nas instalações utilizadas para armazenamento dos insumos } \\
\text { (inseticidas e larvicidas). } \\
\text { - Problemas no controle de estoques de inseticidas e larvicidas. } \\
\text { - Falta de insumos. }\end{array}$ \\
\hline Recursos humanos & $\mathrm{RH}$ & $\begin{array}{l}\text { - Problemas relacionados aos agentes de endemias (número insuficiente, } \\
\text { falta de capacitação, contratação irregular). }\end{array}$ \\
\hline $\begin{array}{l}\text { Aplicação não Autorizada de } \\
\text { recursos }\end{array}$ & ANR & $\begin{array}{l}\text { - Pagamento de despesas inelegíveis com recursos do Bloco da Vigilância } \\
\text { em Saúde. }\end{array}$ \\
\hline Não relacionada ao agente Executor & NRAE & $\begin{array}{l}\text { - Irregularidades não relacionadas à unidade examinada (governos } \\
\text { estaduais e Distrito Federal). }\end{array}$ \\
\hline \multicolumn{3}{|c|}{ Sistema de codificação empregado na análise das justificativas } \\
\hline Categoria & Código & Descrição \\
\hline Causas internas & $\mathrm{Cl}$ & $\begin{array}{l}\text { - O gestor reconhece que a sua gestão não estava aplicando corretamente } \\
\text { os recursos destinados ao combate do Aedes aegypti. }\end{array}$ \\
\hline Causas externas & CE & $\begin{array}{l}\text { - O gestor não reconhece que as irregularidades na aplicação dos recursos } \\
\text { destinados ao combate do Aedes aegypti são de responsabilidade da } \\
\text { sua gestão, atribuindo-as a fatores externos. }\end{array}$ \\
\hline Não apresentou justificativa & NA & $\begin{array}{l}\text { - Ausência de manifestação da unidade examinada (governo estadual e do } \\
\text { Distrito Federal) após a apresentação dos fatos pelos auditores da CGU. }\end{array}$ \\
\hline Justificativa não solicitada pela CGU & NS & - A CGU não solicitou manifestação da unidade examinada. \\
\hline
\end{tabular}

Fonte: Elaborado pelos autores.

Com a finalidade de analisar se a prática de gerenciamento de impressões era prevalente por parte dos gestores estaduais, também foram analisados os estados de forma individualizada com relação ao seu número de irregularidades, bem como ao perfil das justificativas apresentadas por seus gestores. Com base no número de irregularidades, foi feita a seguinte classificação: estados com bom desempenho, desempenho regular e desempenho ruim. Ademais, com base na forma como os gestores justificaram as irregularidades apontadas pela CGU, os estados foram classificados em: nível alto, intermediário ou baixo de accountability. Os critérios para classificação dos estados em cada uma dessas categorias são expostos no Quadro 2.

Para a terceira e a quarta etapas, a classificação das irregularidades conforme as categorias estudadas foi feita de forma individual por dois pesquisadores, os quais analisaram a adequação das categorias propostas. Para a quinta etapa, os pesquisadores confrontaram suas classificações. No caso de divergência entre as classificações propostas, um terceiro pesquisador foi consultado para realizar um parecer sobre a classificação mais adequada. Esse processo foi utilizado de forma a garantir a confiabilidade interna da classificação dos dados. 
Irregularidades na execução dos recursos públicos destinados ao combate do Aedes aegypti nos estados brasileiros: análise do perfil das justificativas apresentadas pelos gestores à luz da Teoria da Atribuição
Daniele Silva Rodrigues | Felipe Rodrigues Cruz Jacqueline Veneroso Alves da Cunha João Estevão Barbosa Neto

\section{Classificação dos estados quanto ao número de irregularidades e quanto ao nível de accountability dos gestores}

\begin{tabular}{|c|l|}
\hline Categoria & \multicolumn{1}{|c|}{ Descrição } \\
\hline $\begin{array}{c}\text { Estados com alto nível } \\
\text { de accountability }\end{array}$ & $\begin{array}{l}\text { Estados que apresentaram um percentual de justificativas baseadas } \\
\text { em causas internas superior a 50\%. }\end{array}$ \\
\hline $\begin{array}{c}\text { Estados com nível } \\
\text { de accountability } \\
\text { intermediário }\end{array}$ & $\begin{array}{l}\text { Estados que apresentaram um percentual de justificativas baseadas } \\
\text { em causas internas igual a 50\%. }\end{array}$ \\
\hline $\begin{array}{c}\text { Estados com nível de } \\
\text { accountability baixo }\end{array}$ & $\begin{array}{l}\text { Estados que apresentaram um percentual de justificativas baseadas } \\
\text { em causas internas inferior a 50\%. }\end{array}$ \\
\hline $\begin{array}{c}\text { Estados com bom } \\
\text { desempenho }\end{array}$ & $\begin{array}{l}\text { Estados que não apresentaram irregularidades e, consequentemente, } \\
\text { não tiveram solicitação de justificativa por parte da CGU. }\end{array}$ \\
\hline $\begin{array}{c}\text { Estados com } \\
\text { desempenho regular }\end{array}$ & $\begin{array}{l}\text { Estados que apresentaram um número de irregularidades inferior } \\
\text { à média de irregularidades. }\end{array}$ \\
\hline $\begin{array}{c}\text { Estados com } \\
\text { desempenho ruim }\end{array}$ & $\begin{array}{l}\text { Estados que apresentaram um número de irregularidades superior } \\
\text { à média. }\end{array}$ \\
\hline
\end{tabular}

Nota: Nesse quadro consideram-se apenas as irregularidades que levaram a CGU a solicitar justificativas dos gestores estaduais. O percentual de justificativas baseadas em causas internas é calculado sobre o total de justificativas solicitadas pela CGU. Além de justificativas baseadas em causas internas, os gestores estaduais poderiam apresentar justificativas baseadas em causas externas ou não apresentar justificativa para as irregularidades. A média de irregularidades foi calculada considerando apenas estados que as apresentavam.

Fonte: Elaborado pelos autores.

Após a aplicação das cinco primeiras etapas da AET, passou-se para a etapa de análise dos dados coletados e classificados. Destaca-se que, no presente trabalho, presume-se que a tendência principal por parte dos gestores seja a de não assumir responsabilidade por suas irregularidades, o que caracterizaria um baixo nível de accountability. Essa expectativa parte da premissa de que os gestores irão atribuir causas externas às suas próprias irregularidades por acreditarem que assumir um erro pode ser politicamente desfavorável. Desse modo, supõe-se que essa tendência de atribuição causal a fatores externos não dependa do nível de desempenho do estado analisado.

Para identificar se o nível de accountability está associado ao desempenho dos estados, estimou-se o teste de Mann-Whitney para diferenças de mediana entre grupos (Mann \& Whitney, 1947). O teste foi realizado com o intuito de identificar se a prática de associar culpa a fatores externos ao controle do gestor é prevalente apenas em estados com desempenho ruim, ou se essa prática é esperada mesmo para estados com desempenho regular. A inexistência de diferença estatística entre os grupos evidenciará que a prática de gerenciamento de impressões é prevalente por parte dos gestores estaduais, independentemente de seu desempenho. Destaca-se que foi adotado um teste não paramétrico com base no resultado do teste de normalidade de Shapiro e Wilk (1965).

\section{RESULTADOS E DISCUSSÕES}

\section{Estatísticas descritivas dos estados}

Inicialmente realizou-se a análise descritiva das características socioeconômicas dos estados, da incidência de casos de dengue (reportada pelo Ministério da Saúde por meio do Boletim Epidemiológico no 3, de 2016) e das irregularidades constatadas pelos auditores da CGU na aplicação dos recursos públicos federais destinados ao combate do Aedes aegypti (Tabela 1). Ressalta-se que são apresentados dados relativos somente aos casos de dengue, uma vez que as estatísticas sobre as demais doenças transmitidas pelo Aedes aegypti (zika e chikungunya) não são reportadas por estados nos boletins epidemiológicos divulgados pelo Ministério da Saúde. 
Irregularidades na execução dos recursos públicos destinados ao combate do Aedes aegypti nos estados brasileiros: análise do perfil das justificativas apresentadas pelos gestores à luz da Teoria da Atribuição
Daniele Silva Rodrigues | Felipe Rodrigues Cruz Jacqueline Veneroso Alves da Cunha João Estevão Barbosa Neto

Tabela 1

Análise descritiva das características socioeconômicas, da incidência de dengue e do total de irregularidades dos estados

\begin{tabular}{l|c|c|c|c|c}
\hline \multicolumn{1}{c|}{ Características } & Média & DP & Mínimo & Máximo & CV (\%) \\
\hline População & 7.182 .669 & 8.907 .007 & 450.479 & 44.396 .484 & 124,00 \\
\hline Área $\left(\mathrm{Km}^{2}\right)$ & $315.329,90$ & $377.420,30$ & 5.802 & 1.570 .745 & 119,69 \\
\hline Valor Fiscalizado (R\$) & $20.923 .938,70$ & $23.176 .675,26$ & $984.523,98$ & $85.927 .264,75$ & 110,77 \\
\hline Incidência de Dengue & 596,66 & 539,80 & 16 & $2.500,60$ & 90,47 \\
\hline Quantidade de Irregularidades & 5,22 & 4,15 & 0 & 14 & 79,50 \\
\hline
\end{tabular}

Nota: o valor fiscalizado corresponde ao montante dos recursos federais destinados ao Bloco da Vigilância em Saúde e fiscalizados pelos auditores da CGU; incidência de dengue: incidência de casos para cada 100 mil habitantes; quantidade de irregularidades: quantidade constatada pela CGU. DP: desvio padrão; CV: coeficiente de variação.

Fonte: Boletim Epidemiológico no 3 de 2016 e Relatórios do Programa de Fiscalização em Entes Federativos da CGU.

Em relação às características socioeconômicas dos 26 estados e do Distrito Federal, observa-se na Tabela 1 que, em média, os estados possuem uma população de, aproximadamente, 7 milhões de habitantes. Ademais, nota-se que cada estado

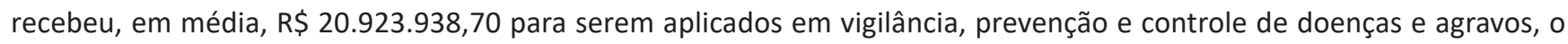
que inclui o combate ao mosquito Aedes aegypti. Destaca-se que esse valor corresponde ao montante de recursos federais destinados aos estados e ao Distrito Federal durante 2015, período no qual os auditores da CGU avaliaram a aplicação dos recursos destinados ao combate do Aedes aegypti.

No que diz respeito às estatísticas divulgadas pelo Ministério da Saúde sobre doenças e agravos, verifica-se que em 2015 foram registrados, em média, 596,66 casos de dengue para cada 100 mil habitantes. Conforme os valores máximo e mínimo da variável que indica a incidência de dengue, nota-se que existem estados, como o Rio Grande do Sul, que apresentaram menos de 20 casos para cada 100 mil habitantes, enquanto em Goiás esse valor foi superior a 2.500 casos.

Em relação às irregularidades constatadas pelos auditores da CGU na aplicação dos recursos federais destinados ao combate do Aedes aegypti, verifica-se que, em média, foram encontradas aproximadamente cinco irregularidades por estado. Todavia nota-se um alto coeficiente de variação das irregularidades apresentadas por cada estado. Na amostra analisada por este estudo, existem estados nos quais não foram constatadas irregularidades na aplicação dos recursos (Pará, Goiás e São Paulo), e outros, como Pernambuco, onde o número de irregularidades foi superior a 13.

São apresentadas na Tabela 2 as estatísticas descritivas de cada tipo de irregularidade constatada pelos auditores da CGU na aplicação dos recursos federais destinados ao combate do Aedes aegypti, considerando toda a amostra do estudo. Foram identificadas 156 irregularidades, dentre as quais 141 foram relacionadas ao agente executor dos recursos.

Tabela 2

Análise descritiva das irregularidades

\begin{tabular}{|c|c|c|c|c|c|c|c|}
\hline Irregularidade & Total & Mediana & Média & DP & Mínimo & Máximo & CV (\%) \\
\hline Licitações e contratos & 24 & 0 & 0,89 & 1,72 & 0 & 8 & 193,26 \\
\hline Desvio de recursos & 18 & 0 & 0,67 & 0,92 & 0 & 3 & 137,31 \\
\hline Desempenho & 49 & 2 & 1,81 & 1,62 & 0 & 6 & 89,50 \\
\hline Infraestrutura & 34 & 1 & 1,26 & 1,40 & 0 & 6 & 111,11 \\
\hline Recursos humanos & 11 & 0 & 0,41 & 1 & 0 & 5 & 243,90 \\
\hline Aplicação não autorizada de recursos & 5 & 0 & 0,19 & 0,48 & 0 & 2 & 252,63 \\
\hline Não relacionada ao agente executor & 15 & 0 & 0,56 & 0,70 & 0 & 2 & 125,00 \\
\hline
\end{tabular}

Nota: DP: desvio padrão; CV: coeficiente de variação.

Fonte: Dados da Pesquisa. 
Irregularidades na execução dos recursos públicos destinados ao combate do Aedes aegypti nos estados brasileiros: análise do perfil das justificativas apresentadas pelos gestores à luz da Teoria da Atribuição
Daniele Silva Rodrigues | Felipe Rodrigues Cruz Jacqueline Veneroso Alves da Cunha João Estevão Barbosa Neto

Com base nas informações expostas na Tabela 2, observa-se que a maior parcela das irregularidades relacionadas ao agente executor é referente ao item desempenho (49 casos -34,75\%). Isso revela que a intempestividade na aplicação dos recursos e a insuficiência de ações para combater o Aedes aegypti são os principais desafios a serem contornados pelos gestores estaduais.

Também foram frequentes a ocorrência de irregularidades do agente executor classificadas nas categorias infraestrutura (34 casos - 24,11\%) e licitações e contratos ( 24 casos - 17,02\%). Em relação ao primeiro tipo de irregularidade, observou-se que houve problemas nas instalações utilizadas para armazenagem dos insumos e no controle de estoque dos inseticidas e larvicidas. Por sua vez, no que diz respeito aos processos de compra com recursos federais destinados ao combate do Aedes aegypti, as seguintes irregularidades foram identificadas pelos auditores da CGU: realização de despesas sem contrato, utilização indevida da dispensa de licitação e indícios de direcionamento e conluio nos processos de dispensa de licitação.

Apesar de o estudo de Olivieri et al. (2018) ter como ponto central os recursos federais destinados à educação básica dos municípios, os resultados foram similares aos da presente pesquisa. Os autores relataram que foram frequentes problemas nas instalações utilizadas para armazenamento de insumos, irregularidades no controle de estoque e indícios de fraudes nos processos licitatórios (direcionamento, conluio e uso indevido de dispensa de licitação). Irregularidades similares nos municípios brasileiros também foram encontradas por Rodrigues et al. (2018) em análise sobre a aplicação dos recursos federais destinados ao PAC, assim como por Araújo e Santos (2018) e Batista (2013) em estudo sobre recursos públicos federais destinados a municípios e estados brasileiros. Essa situação indica similaridades na ocorrência de irregularidades no âmbito estadual e municipal, bem como entre distintos programas contemplados com recursos públicos federais.

O menor número de irregularidades identificadas pela CGU na aplicação dos recursos destinados ao combate do Aedes aegypti refere-se à aplicação não autorizada de recursos (cinco casos - 3,55\%), ou seja, infrações relacionadas ao pagamento de despesas consideradas inelegíveis com os recursos do Bloco da Vigilância em Saúde.

Destaca-se que o presente estudo não teve como objetivo principal a distinção entre corrupção e má aplicação dos recursos públicos, observada em diversos outros trabalhos (vide seção 2.1). No entanto, deve-se ressaltar que, para a população beneficiária dos serviços públicos, ambas as categorias de irregularidade são prejudiciais, pois resultam na redução do potencial benéfico dos recursos distribuídos pela união aos estados, o que implica um combate ineficiente ao Aedes aegypti. Não obstante, alguns insights sobre a diferença das justificativas dos gestores com base nessas categorias (corrupção e má gestão) podem ser extraídos, conforme discutido a seguir.

Diante dos prejuízos gerados pelas irregularidades na gestão dos recursos públicos, buscou-se analisar se os gestores foram capazes de assumir responsabilidade por seus atos. Nas Tabelas 3 e 4, são expostas as estatísticas descritivas relativas aos tipos de justificativa utilizados pelos gestores (causas internas e externas) e os tipos de justificativa referentes a cada classe de irregularidades.

Tabela 3

Análise descritiva das justificativas

\begin{tabular}{l|c|c|c|c|c|c|c}
\hline \multicolumn{1}{c|}{ Irregularidade } & Total & Mediana & Média & DP & Mínimo & Máximo & CV (\%) \\
\hline Causas internas & 9 & 0 & 0,33 & 0,62 & 0 & 2 & 187,88 \\
\hline Causas externas & 61 & 1 & 2,26 & 2,75 & 0 & 10 & 121,68 \\
\hline Não apresentou justificativa & 59 & 0 & 2,19 & 3,92 & 0 & 13 & 179,00 \\
\hline Justificativa não solicitada pela CGU & 12 & 0 & 0,44 & 0,75 & 0 & 3 & 170,45 \\
\hline
\end{tabular}

Nota: DP: desvio padrão; CV: coeficiente de variação.

Fonte: Dados da Pesquisa.

A CGU solicitou justificativas para 129 irregularidades identificadas. Destaca-se que não foram apresentadas justificativas pelos gestores para uma parcela significativa das irregularidades ( 59 casos), embora a CGU as tenha solicitado. Assume-se que essa falta de justificativa por parte dos gestores é prejudicial ao público, o qual é privado de explicações sobre a má utilização de seus recursos arrecadados por meio dos tributos. 
Irregularidades na execução dos recursos públicos destinados ao combate do Aedes aegypti nos estados brasileiros: análise do perfil das justificativas apresentadas pelos gestores à luz da Teoria da Atribuição
Daniele Silva Rodrigues | Felipe Rodrigues Cruz Jacqueline Veneroso Alves da Cunha João Estevão Barbosa Neto

A maior parcela das 70 justificativas apresentadas pelos gestores estaduais e do Distrito Federal indica que as causas das irregularidades observadas foram associadas por estes a fatores que fogem de seu controle (61 casos). Apenas em nove casos os gestores atribuíram a ocorrência de irregularidades a fatores internos. Esse achado alinha-se com as observações de Paschoal et al. (2020) de que os gestores públicos expõem um comportamento de responsabilização de terceiros por suas falhas, bem como se valem de outras justificativas externas.

Dentre as justificativas com base em causas internas dos gestores, conforme se observa na Tabela 4, destaca-se que nenhuma destas está relacionada às irregularidades que ocorreram nos processos licitatórios e nos processos de pagamento relativos ao programa de combate ao Aedes aegypti. Esse é um dado particularmente alarmante, uma vez que, de acordo com a literatura, essas categorias de irregularidades normalmente são associadas à corrupção (Batista, 2013).

O fato de nenhuma das justificativas fornecidas pelos gestores para as irregularidades comumente associadas a atos de corrupção ter sido pautada em fatores internos pode ser um sintoma do potencial da influência política sobre accountability. Embora tanto a má gestão dos recursos públicos quanto a corrupção sejam prejudiciais à sociedade, pode-se assumir que a corrupção é vista de forma menos favorável pelo público. Com base nessa premissa, pode-se interpretar o resultado do presente estudo como um indicativo de que os gestores tendem a considerar essa informação ao apresentar justificativas para suas irregularidades. Não obstante, torna-se improvável que o gestor público assuma responsabilidade por atos que podem ser associados à corrupção, embora, em alguns (raros) casos, assumam a culpa pela má gestão dos recursos públicos.

Tabela 4

Total de justificativas por tipo de irregularidade

\begin{tabular}{l|c|c|c|c|c|c}
\hline \multicolumn{1}{c|}{ Irregularidade } & LIC & DR & DES & INFRA & RH & ANR \\
\hline Causas internas & 0 & 0 & 1 & 7 & 1 & 0 \\
\hline Causas externas & 10 & 7 & 23 & 12 & 6 & 3 \\
\hline Não apresentou justificativa & 13 & 11 & 18 & 13 & 2 & 2 \\
\hline Justificativa não solicitada pela CGU & 1 & 0 & 6 & 3 & 2 & 0 \\
\hline
\end{tabular}

Nota: LIC: Licitações e Contratos; DR: Desvio de Recursos;' DES: Desempenho; INFRA: Infraestrutura;

$R H$ : Recursos Humanos; ANR: Aplicação não Autorizada de Recursos.

Fonte: Dados da Pesquisa.

Os resultados expostos na Tabela 4 revelam que a justificativa dos gestores para eventos negativos tende a ser majoritariamente pautada em causas externas, independentemente do tipo de irregularidade observado. Esses resultados estão em consonância com a premissa do trabalho exposta na seção 2.3, revelando que o viés autosservidor pode exercer um grande impacto sobre a forma como os gestores atribuem causalidade aos eventos negativos no setor público. No contexto organizacional, um comportamento é considerado enviesado e autosservidor quando aqueles que têm mau desempenho tendem a explicá-lo atribuindo um peso maior às características ambientais que fogem ao seu controle (Libby \& Rennekamp, 2012). De forma análoga, no contexto do presente estudo, a atribuição das irregularidades na aplicação de recursos federais a causas externas pode representar um viés no processo atributivo por parte dos gestores estaduais.

Destaca-se que, conforme explicitado anteriormente, as atribuições realizadas pelos indivíduos são afetadas por suas informações, crenças e motivações (Kelley \& Michela, 1980). Isso leva a implicações distintas. Primeiramente, a atribuição dos gestores pode ser ocasionada por suas limitações cognitivas. Nesse caso, os gestores estaduais podem estar sendo incapazes de reconhecer suas limitações na aplicação dos recursos federais para combater o Aedes aegypti, o que revela um aspecto preocupante da gestão estadual, principalmente quando se considera a inefetividade do programa de combate ao mosquito Aedes aegypti.

A atribuição de irregularidades a fatores externos também pode estar relacionada à intenção dos gestores de praticar o gerenciamento de impressão, com a finalidade de melhorar a imagem de sua gestão perante a sociedade. Essa possibilidade é plausível quando se considera o forte contexto de incentivo para o gerenciamento de impressões em que esses gestores se inserem (Aerts, 2005), afinal, buscam sua reeleição ou a eleição de algum candidato da base aliada (intimamente ligada à manutenção de seus cargos). 
Irregularidades na execução dos recursos públicos destinados ao combate do Aedes aegypti nos estados brasileiros: análise do perfil das justificativas apresentadas pelos gestores à luz da Teoria da Atribuição
Daniele Silva Rodrigues | Felipe Rodrigues Cruz Jacqueline Veneroso Alves da Cunha João Estevão Barbosa Neto

Esse comportamento oportunista pode vir a ser prejudicial, pois os aplicadores de recursos buscam atribuir a inefetividade do programa a fatores que não são de seu controle, o que pode prolongar a atuação de indivíduos que não estão apropriadamente capacitados para a tarefa do programa de combate ao mosquito. Isso ocorre pelo fato de que a distorção das informações causada pela motivação pessoal do gestor público pode implicar uma maior assimetria informacional entre o gestor e a sociedade, prejudicando a tomada de decisão dos indivíduos em processos eleitorais, por exemplo. Desse modo, percebe-se que a prática de gerenciamento de impressão por parte dos gestores públicos constitui um problema que deve ser monitorado, para que a efetividade da gestão pública e a lisura dos processos eleitorais não sejam prejudicadas.

Em geral, os achados apontam para um baixo nível de accountability por parte dos gestores estaduais. Um aspecto que pode influenciar os resultados obtidos na presente seção é o tratamento conjunto de toda a amostra relativa a tais gestores. Assim, na próxima seção são realizados testes estatísticos para controlar se o resultado relativo à accountability dos gestores está associado ao nível de desempenho dos gestores de estados específicos.

\section{Análise da associação do desempenho e do nível de accountability dos gestores}

Na seção anterior, demonstrou-se que a maior parte das justificativas dos gestores estaduais foi aparentemente motivada pelo viés autosservidor, conforme a premissa de que as motivações políticas iriam influenciar as atribuições causais. Isso revela que, de forma geral, os gestores estaduais brasileiros apresentam baixo accountability.

Seria possível argumentar que gestores de estados menos eficientes estariam afetando a média da amostra. No entanto, quando se analisam os estados de forma individual, percebe-se que não é esse o caso, conforme se observa nos dados descritivos expostos na Tabela 5 e na comparação de medianas na Tabela 6.

Tabela 5

Estatística descritiva do desempenho e do nível de accountability dos estados

\begin{tabular}{|c|c|c|c|}
\hline Categoria & Estados & Total & Percentual \\
\hline Estados que foram solicitados a apresentar justificativas à CGU. & $\begin{array}{l}\text { AC, AL, AP, AM, BA, CE, DF, ES, } \\
\text { MA, MS, MT, MG, PB, PR, PE, PI, } \\
\text { RJ, RN, RS, RO, RR, SC, SE, TO }\end{array}$ & 24 & $88.89 \%$ \\
\hline $\begin{array}{l}\text { Estados com alto accountability: percentual de justificativas } \\
\text { baseadas em causas internas superior a 50\%. }\end{array}$ & $\mathrm{AL}$ & 1 & $3.70 \%$ \\
\hline $\begin{array}{l}\text { Estados com nível intermediário de accountability: percentual } \\
\text { de justificativas baseadas em causas internas igual a 50\%. }\end{array}$ & AM, ES & 2 & $7.41 \%$ \\
\hline $\begin{array}{l}\text { Estados com baixo accountability: justificativas com base } \\
\text { em fatores externos e/ou a ausência de justificativas foram } \\
\text { prevalentes (mais que 50\%). }\end{array}$ & $\begin{array}{l}\text { AC, } A P, B A, C E, D F, M A, M S, M T \\
M G, P B, P R, P E, P I, R J, R N, R S \\
\quad R O, R R, S C, S E, T O\end{array}$ & 21 & $77.78 \%$ \\
\hline $\begin{array}{l}\text { Estados que não apresentaram justificativas para } 50 \% \text { ou mais } \\
\text { irregularidades apontadas pela CGU. }\end{array}$ & $A P, C E, D F, M T, P E, R N, R S$ & 7 & $25.93 \%$ \\
\hline $\begin{array}{l}\text { Estados que não apresentaram justificativas sobre as } \\
\text { irregularidades apontadas pela CGU. }\end{array}$ & $\mathrm{MT}, \mathrm{PE}, \mathrm{RN}, \mathrm{RS}$ & 4 & $14.81 \%$ \\
\hline $\begin{array}{l}\text { Estados com bom desempenho: não tiveram solicitação de } \\
\text { justificativa por parte da CGU. }\end{array}$ & GO, PA e SP & 3 & $11.11 \%$ \\
\hline $\begin{array}{l}\text { Estados com desempenho ruim: apresentaram um número } \\
\text { superior à média de solicitações }(5,35) \text { de justificativas para as } \\
\text { irregularidades apontadas pela CGU. }\end{array}$ & $A C, B A, D F, M T, P B, P E, R N, S E$ & 8 & $29.63 \%$ \\
\hline $\begin{array}{l}\text { Estados com desempenho regular: apresentaram um número } \\
\text { inferior à média de solicitações }(5,35) \text { de justificativas para as } \\
\text { irregularidades apontadas pela CGU. }\end{array}$ & $\begin{array}{l}A L, A P, A M, C E, E S, M A, M S, M G \\
\quad P R, P I, R J, R S, R O, R R, S C, T O\end{array}$ & 16 & $59,26 \%$ \\
\hline
\end{tabular}

Fonte: Dados da Pesquisa. 
Irregularidades na execução dos recursos públicos destinados ao combate do Aedes aegypti nos estados brasileiros: análise do perfil das justificativas apresentadas pelos gestores à luz da Teoria da Atribuição
Daniele Silva Rodrigues | Felipe Rodrigues Cruz Jacqueline Veneroso Alves da Cunha João Estevão Barbosa Neto

Na Tabela 5 são expostos os estados cujas irregularidades tiveram solicitação de justificativa por parte da CGU aos gestores e também a forma como estes manifestaram-se sobre elas. Os resultados expostos nessa tabela permitem que se identifiquem quais foram os estados com maior número de irregularidades, assim como o nível de accountability dos gestores de cada unidade federativa. Destaca-se que, objetivando simplificar a apresentação dos resultados da presente seção, o termo "irregularidades" será utilizado para se referir apenas àquelas para as quais a CGU solicitou justificativas aos gestores estaduais.

Somente três dos estados analisados não tiveram solicitação de justificativa por parte da CGU (GO, PA e SP) e foram classificados como estados com bom desempenho. Os demais foram classificados em grupos de "desempenho regular" ou "desempenho ruim", que são, respectivamente, aqueles com um número de irregularidades abaixo ou acima da média de irregularidades de todos os estados (5,35 irregularidades). $O$ alto nível de estados que apresentam irregularidades é condizente com a ampla evidência na literatura de má aplicação dos recursos públicos e da incidência de corrupção na gestão destes (Batista, 2013; Laurinho et al., 2017; Rodrigues et al., 2018; dentre outros) e reforça a importância do acesso à informação de qualidade por parte da sociedade para que esta possa avaliar a gestão pública e tomar decisões acertadas nos processos eleitorais.

Dentre as 24 unidades do território brasileiro com desempenho ruim ou regular, apenas uma (AL) apresentou um percentual de justificativas classificadas como "causas internas" superior ao percentual de justificativas classificadas como "causas externas". Logo, apenas um estado apresentou um nível elevado de accountability por parte de seus gestores, com uma irregularidade somente. Ademais, apenas em dois estados (ES e AM) o percentual de justificativas atribuídas a fatores externos foi igual ao atribuído a fatores internos ( $50 \%$ para cada). Este percentual foi classificado como de nível intermediário de accountability. Em 21 estados, o número de justificativas com base em fatores externos e/ou a ausência de justificativas foram prevalentes, o que revela um baixo accountability.

Percebe-se que é rara a atribuição de culpa a fatores controláveis por parte da maior parcela dos gestores de estados que apresentaram irregularidades, com poucas exceções. Nesse contexto, foi realizado um teste de Mann-Whitney (Tabela 6) para investigar se existe uma associação entre uma maior capacidade de accountability e o desempenho do estado em termos de irregularidades. Destaca-se que a opção pelo teste de Mann-Whitney em detrimento do teste t deve-se ao fato de se tratar de uma amostra pequena e também em virtude de as variáveis comparadas não apresentarem distribuição normal de acordo com o teste de Shapiro-Wilk ao nível de 5\%.

Tabela 6

Comparação de estados com diferentes desempenhos em relação às suas justificativas

\begin{tabular}{|c|c|c|c|c|c|c|}
\hline Grupo & \multicolumn{2}{|c|}{$\begin{array}{l}\text { Estados com total de } \\
\text { irregularidades inferior à } \\
\text { média (desempenho regular) }\end{array}$} & \multicolumn{2}{|c|}{$\begin{array}{l}\text { Estados com total de } \\
\text { irregularidades superior à } \\
\text { média (desempenho ruim) }\end{array}$} & \multicolumn{2}{|c|}{$\begin{array}{l}\text { Teste de } \\
\text { Mann-Whitney }\end{array}$} \\
\hline Número de observações & \multicolumn{2}{|c|}{16} & \multicolumn{2}{|c|}{8} & \multicolumn{2}{|c|}{24} \\
\hline Estatísticas & Mediana & Média & Mediana & Média & z & prob $>z$ \\
\hline $\begin{array}{l}\text { Percentual de justificativas com base em } \\
\text { causas internas }\end{array}$ & 0 & $16,14 \%$ & 0 & $5,14 \%$ & $-0,610$ & 0,5418 \\
\hline Percentual de irregularidades sem justificativas & 0 & $20,63 \%$ & $56,95 \%$ & $51,74 \%$ & 1,575 & 0,1153 \\
\hline
\end{tabular}

Nota: Foi utilizado o teste bicaudal de Wilcoxon para a mediana. Nenhum dos grupos apresentou mediana estatisticamente diferente ao nível de $5 \%$ de significância.

A significância da estatística $z$ ( rob $>z$ ) indica se o grupo de firmas com desempenho ruim apresenta mediana estatisticamente superior (z positivo) ou inferior (z negativo) ao grupo com desempenho regular.

O nível de accountability foi mensurado como o percentual de justificativas baseadas em causas internas.

Fonte: Dados da Pesquisa.

Com base na análise do teste de Mann-Whitney, percebe-se que os estados com um número acima da média de irregularidades para as quais a CGU solicitou justificativas - apresentaram níveis de atribuição causal a fatores internos estatisticamente semelhantes aos apresentados por estados com menores níveis de irregularidade ao nível de $5 \%$ de significância. Isso evidencia que a prática de atribuir culpa a fatores externos e a ausência de justificativas são prevalentes tanto nos estados com níveis elevados de irregularidade (desempenho ruim), quanto naqueles em que o total de irregularidades é inferior à média (desempenho regular). Logo, embora intuitivamente se possa acreditar que gestores mais eficazes tendem a assumir 
Irregularidades na execução dos recursos públicos destinados ao combate do Aedes aegypti nos estados brasileiros: análise do perfil das justificativas apresentadas pelos gestores à luz da Teoria da Atribuição
Daniele Silva Rodrigues | Felipe Rodrigues Cruz Jacqueline Veneroso Alves da Cunha João Estevão Barbosa Neto

responsabilidade e/ou à autocritica, observa-se que esses comportamentos não variam de acordo com o desempenho dos gestores na aplicação dos recursos públicos (medida pelo número de irregularidades).

Em suma, as evidências apontam para uma tendência de rejeição da culpa por parte dos gestores, independentemente do nível de desempenho destes. Pode-se argumentar que esse tipo de postura tem a finalidade de influenciar a opinião pública, 0 que tende a prejudicar o processo eleitoral e, consequentemente, a qualidade da prestação de serviço por parte da máquina pública. Essa explicação é compatível com a interpretação motivacional da Teoria da Atribuição (Aerts, 2005; Birnberg et al., 1977; Kelley \& Michela, 1980).

Destaca-se que, embora a interpretação baseada em limitações cognitivas também possa se adequar aos resultados do presente estudo, a explicação motivacional possui maior capacidade de explicar o fato de nenhum dos gestores ter apresentado atribuição causal a fatores internos para as irregularidades comumente associadas a atos de corrupção. Considerando-se o aspecto motivacional atrelado à vida política, esse achado revela que os gestores evitam que sua imagem seja atrelada a atos condenados pela sociedade ativa, principalmente quando o grau de reprovação ao ato é mais elevado, como é o caso da corrupção.

\section{CONSIDERAÇÕES FINAIS}

O objetivo desta pesquisa foi identificar o perfil das justificativas apresentadas pelos gestores estaduais e do Distrito Federal para as irregularidades observadas pelos auditores da CGU na utilização dos recursos federais destinados ao combate do Aedes aegypti. Para atingir esse objetivo, recorreu-se à análise de conteúdo em conjunto com a análise de estatísticas descritivas e do teste de Mann-Whitney. A base norteadora da análise foi o arcabouço da Teoria da Atribuição, que auxilia no entendimento de como os indivíduos atribuem causalidade a eventos.

Dentre as categorias de irregularidades consideradas, os resultados do estudo apontaram que as que registraram o maior número de constatações foram as seguintes: desempenho; estrutura; e licitações e contratos. Esses achados indicaram que foram frequentes: i) a intempestividade na aplicação dos recursos públicos federais destinados ao combate do Aedes aegypti, ii) problemas nas instalações utilizadas para armazenagem dos insumos e no controle de estoque dos inseticidas e larvicidas; e iii) realização de despesas sem contrato, utilização indevida da dispensa de licitação e indícios de direcionamento e conluio nos processos de dispensa de licitação.

Destaca-se que a CGU solicita aos gestores justificativas para essas irregularidades. Quando indivíduos - nesse caso, os gestores buscam uma causa explicativa específica para a realização de uma tarefa, "[...] tendem a experimentar reações emocionais específicas que, por sua vez, influenciam significativamente a percepção de expectativas de comportamentos e de resultados futuros" (Dela Coleta \& Alves Godoy, 1986, p. 1). Embora seja prática cotidiana de gestores públicos fazerem atribuições, é preciso atentar-se para o fato de que elas nem sempre são corretas, podendo ocorrer, em situação de irregularidades, o caso de um gestor subestimar a influência de fatores pessoais e superestimar a influência de fatores situacionais ao avaliar os resultados da gestão de recursos públicos sob sua responsabilidade. Ou seja, ao observar a ocorrência de fraudes, é mais provável que uma pessoa assuma que tal ocorrência se deu mais por um fator externo e menos por sua ação. Isso contribui para uma distorção do entendimento da sociedade sobre a gestão daqueles recursos e, consequentemente, para o mal entendimento e aceitação do erro por parte dos cidadãos.

No que diz respeito às justificativas apresentadas pelos gestores estaduais no contexto do combate ao Aedes aegypti, os resultados da pesquisa demonstraram que, independentemente do tipo de irregularidade observada, a justificativa dos gestores estaduais para eventos negativos tende a ser pautada em causas externas. Esses resultados revelam que o viés autosservidor pode exercer um grande impacto sobre a forma como os gestores atribuem causalidade aos eventos negativos. Um aspecto relevante é o de que a motivação para a associação causal a fatores externos é maior quando se trata de irregularidades que podem ser interpretadas como atos de corrupção.

$O$ viés autosservidor dos gestores em relação às suas irregularidades pode constituir um desafio à consecução dos objetivos do programa de combate à dengue, pois estes tendem a não destacar os fatores internos que afetam seus resultados. 
Irregularidades na execução dos recursos públicos destinados ao combate do Aedes aegypti nos estados brasileiros: análise do perfil das justificativas apresentadas pelos gestores à luz da Teoria da Atribuição
Daniele Silva Rodrigues | Felipe Rodrigues Cruz Jacqueline Veneroso Alves da Cunha João Estevão Barbosa Neto

Esse tipo de visão pode levar os gestores, quando não reconhecem que os aspectos sob seu controle não foram satisfatórios, a não se atentarem aos fatores de sua própria atuação que podem sofrer melhorias.

Destaca-se que não se pode descartar a possibilidade de que estes gestores entendam os fatores internos que levaram às irregularidades, embora não os reconheçam em suas justificativas. Esse tipo de comportamento pode ser motivado pela tentativa de gerenciamento de impressão, afinal, os gestores buscam apresentar uma boa imagem perante a sociedade. Não obstante, esse tipo de comportamento atribucional também pode ser considerado ruim para a gestão pública, pois pode levar à reeleição de gestores que foram ineficientes na aplicação dos recursos federais.

Uma interpretação alternativa ao gerenciamento de impressões é a de que os gestores efetivamente percebem que a causa da irregularidade está fora de seu controle. No entanto, isso pode implicar relutância por parte destes em tentar ações para uma melhor gestão. Desse modo, entender as atribuições (justificativas) das pessoas pode ter um forte efeito no desempenho do gestor e na eficácia gerencial.

Diante do exposto, os resultados do presente estudo contribuem para demonstrar a importância de avaliação e acompanhamento dos gestores públicos e de suas ações, bem como de suas explicações diante de irregularidades e/ou ineficiências na execução de ações de combate à epidemia de zika, dengue, chikungunya. Assim, conhecendo as causas positivas ou negativas da gestão dos recursos no combate ao Aedes aegypti, o cidadão terá um maior conhecimento das atuações dos gestores públicos, podendo exercer o controle social e contribuir também para o controle institucional realizado pelos órgãos fiscalizadores dos recursos públicos.

Outra contribuição desta pesquisa está no conhecimento sobre como os gestores explicam as causas do seu comportamento e de sua gestão. Assim, os responsáveis pelos recursos públicos agem com base em suas atribuições e possivelmente de forma inadequada se as atribuições não forem válidas. Conhecer melhor a percepção desses indivíduos contribui para o aperfeiçoamento da própria gestão dos recursos públicos, principalmente os destinados ao combate a epidemias. Por meio do melhor entendimento de como os gestores justificam suas ações, novas perspectivas, dinâmicas e instrumentos podem ser utilizados para que os recursos sejam mais bem utilizados e os serviços públicos prestados com mais qualidade. A fiscalização dos gastos também pode ser aperfeiçoada. Assim, tanto a gestão, quanto a fiscalização precisam ser continuamente modernizadas, eficientes e efetivas, para acompanhar a evolução das necessidades sociais.

Este estudo apresentou algumas limitações. Um aspecto limitativo foi a base de dados utilizada para a identificação das irregularidades. Apesar de os relatórios da CGU serem frequentemente utilizados na literatura, eles focam somente na aplicação dos recursos federais destinados aos estados e municípios. Dessa forma, existem outras fontes de dados que podem ser utilizadas para a mensuração de problemas na aplicação dos recursos públicos, como os relatórios de auditoria dos Tribunais de Contas.

É necessário que as premissas do presente estudo sejam testadas no contexto de outros programas para os quais são destinados recursos públicos. Nesse sentido, outra importante limitação que merece destaque é a de que os achados desta pesquisa não podem ser generalizados, ou seja, são restritos apenas ao período e à amostra aqui contemplados. Entretanto, pode-se presumir que o viés autosservidor estará presente nos contextos de aplicação de recursos federais em outros programas, o que pode ser um tópico interessante a ser analisado em estudos futuros. Sugere-se, desse modo, que futuras pesquisas analisem as justificativas apresentadas pelos gestores públicos em outras áreas, como educação e assistência social. Novos estudos possibilitarão uma comparação entre estas áreas, assim como uma possível generalização dos resultados do presente trabalho.

\section{AGRADECIMENTOS}

À Fundação de Amparo à Pesquisa do Estado de Minas Gerais. Bolsa de Doutorado Daniele Silva Rodrigues. 
Irregularidades na execução dos recursos públicos destinados ao combate do Aedes aegypti nos estados brasileiros: análise do perfil das justificativas apresentadas pelos gestores à luz da Teoria da Atribuição
Daniele Silva Rodrigues | Felipe Rodrigues Cruz Jacqueline Veneroso Alves da Cunha João Estevão Barbosa Neto

\section{REFERÊNCIAS}

Aerts, W. (2005). Picking up the pieces: impression management in the retrospective attributional framing of accounting outcomes. Accounting, Organizations and Society, 30(6), 493-517.

Albuquerque, B. E.; \& Ramos, F. S. (2006). Análise teórica e empírica dos determinantes de corrupção na gestão pública municipal. In Anais do Encontro Nacional de Economia, Salvador, BH.

Araújo, L. P., \& Santos, N. A. (2018). Evidências empíricas de desperdícios ativos e passivos na execução de programas de governo pelos estados. In Proceedings of the International Conference in Accounting e Congresso USP de Iniciação Científica em Contabilidade, São Paulo, SP.

Barata, R. B. (2000). Cem anos de endemias e epidemias. Ciências \& Saúde Coletiva, 5(2), 333-345.

Bardin, L. (1977). Análise de conteúdo. São Paulo, SP: Edições 70.

Batista, M. (2013). Incentivos da dinâmica política sobre a corrupção: reeleição, competitividade e coalizões nos municípios brasileiros. Revista Brasileira de Ciências Sociais, 28(82), 87-106.

Batista, M., Rocha, V. E, \& Santos, J. L. A. (2020). Transparência, corrupção e má gestão: uma análise dos municípios brasileiros. Revista de Administração Pública, 54(5), 1382-1401.

Birnberg, J. G., Frieze, I. H., \& Shields, M. D. (1977). The role of attribution theory in control systems. Accounting, Organizations and Society, 2(3), 189-200.

Birnberg, J. G., Luft, J., \& Shields, M. D. (2007). Psychology theory in management accounting research. In C. S. Chapman, A. G. Hopwood, \& M. D. Shields (Eds.), Handbook of Management accounting research. Chicago, IL: Elsevier.

Controladoria Geral da União. (2016). Programa de Fiscalização em Entes Federativos: 2o Ciclo. Recuperado de http://www.cgu.gov.br/assuntos/auditoria-e-fiscalizacao/ programa-de-fiscalizacao-em-entes-federativos/2-ciclo

Controladoria Geral da União. (2018). Programa de Fiscalização em Entes Federativos. Recuperado de http://www.cgu.gov.br/assuntos/ auditoria-e-fiscalizacao/programa-de-fiscalizacao-em-entes-federativos

Dela Coleta, J. A., \& Alves Godoy, S. (1986). Atribuição de causalidade ao sucesso e fracasso e reações emocionais: pesquisas brasileiras com os modelos de Bernard Weiner. Psicologia: Teoria e Pesquisa, 2(2), 145-156.

Ferraz, C., \& Finan, F. (2008). Exposing corrupt policiticans: the effects of Brazil's publicily released audits on electoral outcomes. Quarterly Journal of Economics, 123(2), 703-745.

Formiga, N. S. (2004). Atribuição de causalidade e rendimento acadêmico: predição e diferença em alunos da universidade pública e privada. Revista de Psicologia da UnC, 2(2), 3-14.

Fundação Oswaldo Cruz. (2020). Gestão de riscos e governança na pandemia por Covid-19 no Brasil: Análise dos decretos estaduais no primeiro mês. Recuperado de https://www.arca.fiocruz.br/handle/ icict/41452

Gouveia, V. V., Clemente, M., Ángel, M. A., \& Martínez, E. (2000). Atribuição de responsabilidade social: contexto social e atributos pessoais do observador. Revista de Psicologia Social, 15(2), 153-163.
Heider, F. (1958). The psychology of interpersonal relations. Nova York, NY: Wiley.

Januzzi, P. M. (2011). Avaliação de Programas Públicos por Meio da Análise Estruturada dos Relatórios de Auditoria da Controladoria Geral da União. Cadernos Gestão Pública e Cidadania, São Paulo, 16(59), 228-239.

Kelley, H. H., \& Michela, J. L. (1980). Attribution theory and research. Annual review of psychology, 31(1), 457-501.

Laurinho, I. S., Dias, L. N. S., \& Mattos, C. A. C. (2017). Corrupção e ineficiência em licitações de governos locais e desenvolvimento humano: novas reflexões. Revista de Contabilidade e Organizações, 30, 57-70.

Libby, R., \& Rennekamp, K. (2012). Self-serving attribution bias, overconfidence, and the issuance of management forecasts. Journal of Accounting Research, 50(1), 197-231.

Lopes, B. J., \& Doula, S. M. (2019). Deficiências no Processo de Compras Governamentais do Programa Nacional de Alimentação Escolar e seus Impactos no Desenvolvimento Local. Desenvolvimento em Questão, 17(48), 175-192.

Mann, H. B., \& Whitney, D. R. (1947). On a test of whether one of two random variables is stochastically larger than the other. The Annals of Mathematical Statistics, 18(1) 50-60.

Merkl-Davies, D. M., \& Brennan, N. (2017). A theoretical framework of external accounting communication: Research perspectives, traditions, and theories. Accounting, Auditing and Accountability Journal, 30(2), 433-469.

Ministério da Saúde. (2015). Portaria no 1.813, de 11 de novembro de 2015. Declara Emergência em Saúde Pública de importância Nacional (ESPIN) por alteração do padrão de ocorrência de microcefalias no Brasil. Recuperado de http://bvsms.saude.gov.br/bvs/saudelegis/ gm/2015/prt1813_11_11_2015.html.

Ministério da Saúde. (2016a). Boletim Epidemiológico no 3 de 2016. Brasília, DF, 2016a. Recuperado de http://portalms.saude.gov.br/ boletins-epidemiologicos

Ministério da Saúde. (2016b). Boletim Epidemiológico no 1 de 2016. Brasília, DF. Recuperado de http://portalms.saude.gov.br/ boletins-epidemiologicos

Ministério da Saúde. (2016c). Prevenção e combate-Dengue, Chikungunya e Zika: Plano Nacional de Enfrentamento. Brasília, DF, 2016c. Recuperado de http://www.combateaedes.saude.gov.br/ pt/plano-nacional

Ministério da Saúde. (2017a). Prevenção e combate - Dengue, Chikungunya e Zika: Linha do Tempo. Brasília, DF. Recuperado de http://www.combateaedes.saude.gov.br/pt/linha-do-tempo

Ministério da Saúde. (2017b). Boletim Epidemiológico no 3 de 2017. Brasília, DF. Recuperado de http://portalms.saude.gov.br/ boletins-epidemiologicos

Olivieri, C., Martinelli, B., Massucato, P., \& Silva, C. B. (2018). Gestão municipal e corrupção na implementação de programas educacionais federais. Revista de Administração Pública, 52(1), 169-179. 
Irregularidades na execução dos recursos públicos destinados ao combate do Aedes aegypti nos estados brasileiros: análise do perfil das justificativas apresentadas pelos gestores à luz da Teoria da Atribuição
Daniele Silva Rodrigues | Felipe Rodrigues Cruz Jacqueline Veneroso Alves da Cunha João Estevão Barbosa Neto
Paschoal, A. L. P., Santos, N. A., \& Faroni, W. (2020). Diamante da fraude: evidências empíricas nos relatórios de demandas externas do Ministério da Transparência e Controladoria Geral da União (CGU) dos municípios brasileiros. Revista Ambiente Contábil, 12(2), 136-156.

Rodrigues, D. S., Faroni, W., Santos, N. A., Ferreira, M. A. M., \& Diniz, J. A. (2020). Corrupção e má gestão nos gastos com educação: fatores socioeconômicos e políticos. Revista de Administração Pública, 54(2), 301-320.

Rodrigues, D. S., Santos, N. A., \& Faroni, W. (2018). Programa de Aceleração do Crescimento (PAC): um estudo descritivo sobre os desperdícios ativos e passivos. Revista Catarinense da Ciência Contábil, 17(50), 89-105.
Shapiro, S. S., \& Wilk, M. B. (1965). An analysis of variance test for normality (complete samples). Biometrika, 52(3/4), 591-611.

Tessarolo, I. F., Pagliarussi, M. S., \& Luz, A. T. M. D. (2010). The justification of organizational performance in annual report narratives. BAR-Brazilian Administration Review, 7(2), 198-212.

Tribunal de Contas da União. (2017). Relatório de Acompanhamento: TC 023.421/2016-9. Brasília, DF. Recuperado de https://contas.tcu.gov.br/etcu/ObterDocumentoSisdoc? seAbrirDocNoBrowser=true \&codArqCatalogado=12641035

Zamboni, Y. B., Filho. (2012). Avaliando o avaliador: evidências de um experimento de campo sobre as auditorias da CGU (Tese de Doutorado). Fundação Getulio Vargas, São Paulo, SP.

Daniele Silva Rodrigues

ORCID: https://orcid.org/0000-0002-6672-1236

Doutoranda em Controladoria e Contabilidade da Universidade Federal de Minas Gerais (UFMG). E-mail: silvar.daniele@gmail.com

Felipe Rodrigues Cruz

ORCID: http://orcid.org/0000-0003-4837-9323

Doutorando em Controladoria e Contabilidade da Universidade Federal de Minas Gerais (UFMG). E-mail: felipe.rcruz11@gmail.com

Jacqueline Veneroso Alves da Cunha

ORCID: https://orcid.org/0000-0003-2522-3035

Doutora em Controladoria e Contabilidade da Universidade de São Paulo (USP); Professora associada da Universidade Federal de Minas Gerais (UFMG)

E-mail: jvac@face.ufmg.br

João Estevão Barbosa Neto

ORCID: https://orcid.org/0000-0001-5197-2166

Doutor em Controladoria e Contabilidade da Universidade de São Paulo (USP); Professor adjunto da Universidade Federal de Minas Gerais (UFMG)

E-mail: joaoestevaobn@face.ufmg.br 